\title{
Tendencias actuales en los estudios del Antiguo Testamento. Desafíos y oportunidades
}

\author{
Ignacio Chuecas
}

Antes de entrar directamente en el tema es necesario hacer una observación preliminar que, a mi modo de ver, tiene gran influencia sobre la materia de este estudio y, que a su vez, representa una diferencia importante entre el campo de los estudios bíblicos y el de la teología sistemática.

Me refiero a la gran amplitudy diversidad que han alcanzado este tipo de estudios en la actualidad. A modo de ejemplo, una muestra de este fenómeno es la gran cantidad de investigadores comprometidos con las Escrituras del Antiguo y del Nuevo Testamento. La Society of Biblical Literature, probablemente la asociación más importante a nivel mundial pero no la única, cuenta actualmente con 8.697 miembros, según su último informe. En el congreso anual del año 2008 participaron 5.501 investigadores: se trata de un megaevento llevado a cabo cada año en una ciudad norteamericana distinta.

Al mismo tiempo, es posible imaginarse la gran cantidad de publicaciones que ven la luz anualmente, lo que virtualmente plantea grandes dificultades para todo aquel que desee hacerse una idea global de los últimos trends en el desarrollo de la disciplina.

Evidentemente, este fenómeno de tan gran difusión y producción científica lleva de la mano un siempre creciente grado de especialización en relación a las diferentes secciones del texto bíblico, y en relación a las materias y métodos conectados con este. Las nuevas impostaciones en el estudio de los textos representan un desafío adicional para quienquiera ganar un panorama amplio, porque exigen un grado de familiaridad con ellas que no es evidente. 


\section{Cambio en los paradigmas Clásicos}

Uno de los elementos más notorios en las tendencias actuales en cuanto al estudio del AT es el cambio que se puede observar en los paradigmas clásicos. Este cambio puede ser resumido, en forma bastante ruda, como un cambio de perspectiva en relación al material bíblico: se trata del creciente abandono de la diacronía en favor de la sincronía.

El fenómeno de una atención cada vez mayor hacia la perspectiva sincrónica, podría ser descrito, con otras palabras, como la «irrupción de la literatura» en el campo de los estudios ${ }^{1}$. Al cabo de varios siglos de investigación científica en torno a los textos, por primera vez, de una forma más consecuente, la investigación ha comenzado a preguntarse cómo escribían los antiguos, qué significaba y cómo se generaba un texto en el contexto cultural del antiguo Israel ${ }^{2}$.

Este nuevo impulso generado en torno a la investigación sincrónica se fundamenta en un postulado central: se trata de asumir el texto como este se presenta en la actualidad, el texto "tal cual es». La búsqueda diacrónica de los niveles más antiguos de la redacción, ha comenzado a ceder el paso al texto como una obra artística, cuya elocuencia se expresa en su forma final y cómo esta se nos presenta. Cercana a esta afirmación, se ha de afincar, a mi entender, aunque claramente son nociones que no tienen la misma matriz, otro tema muy vigente en la actualidad: el fenómeno canónico ${ }^{3}$.

Este retorno al texto es producto de varias anomalías denunciadas por los investigadores. Una de las más influyentes ha sido la noción de que se había arribado a trabajar con un metatexto que ya no representaba al texto real.

Una obra precursora en el campo de la narrativa ha sido: R. Alter, The Art of the Biblical Narrative (New York 1981). Cf. también: R. Alter, The Art of Biblical Poetry (Edinburgh 1985); S. Bar-Efrat, Narrative Art in the Bible (Sheffield 1989); D. M. Gunn - D. Nolan Fewell, Narrative in the Hebrew Bible (Oxford 1993).

2 Un intento de resumen sobre algunas de estas nuevas percepciones en: I. CHuecas, “¿¿Entiendes, con seguridad, lo que lees?” Hch 8,30. Caminos de la hermenéutica de [en] la Escritura», Teología y Vida 45 (2004) 75-102.

3 Cf. B. S. Childs, Old Testament Theology in Canonical Context (Philadelphia 1986); R. Rendtorff, Theologie des Alten Testaments, Ein kanonischer Entwurf (Neukirchen-Vluyn 1999). 
En otros campos, y en conformidad con desarrollos afines en las ciencias humanistas, como la historia, están ejerciendo una influencia decisiva las nuevas impostaciones relacionadas con la arqueología, la sociología, los estudios feministas, y un sinnúmero de otras disciplinas ${ }^{4}$. Para citar solo un botón de muestra: del ámbito de la sociología se observan importantes aportes que están influenciando fuertemente nuestra visión de la sociedad que generó estos escritos en el contexto del universo social del mediterráneo antiguo, introduciendo, entre otros, el concepto de «sociedad colonial» con todas las implicaciones que este tiene $e^{5}$.

Por último es posible observar una superación, cada vez mayor, de las barreras que tradicionalmente existían entre el AT y el NT ${ }^{6}$. Este proceso se debe, a mi entender, a varias causas: la creciente importancia conferida a la literatura intertestamentaria, especialmente desde el hallazgo de los textos de Qumrán; el interés de investigadores no cristianos, especialmente judíos, en el NT; los impulsos desde el campo de la historiografía y las ciencias sociales que aportan una mirada global en relación a las sociedades mediterráneas del mundo antiguo, etc.

\section{Historia de IsRael}

Una disciplina que está influyendo fuertemente en la investigación actual en torno al AT es la investigación histórica. Pero antes de desarrollar este tema es necesario precisar una cierta diferenciación en relación a la naturaleza de los libros que, tradicionalmente, llamamos históricos al interior del AT. En cuanto a esta naturaleza es pertinente aclarar que la categoría de históricos se ha de entender como aquello que los identifica más bien ad intra del corpus bíblico, se trata de una percepción relativa a sus motivos y sus fines, y de la forma cómo estos son presentados al lector, en otras palabras, su teología. A esta materia me dedicaré en el punto cuarto de este estudio.

4 Cf. N. K. GotTwald, The Hebrew Bible, A Brief Socio-Literary Introduction (Minneapolis 2009) 3-19.

5 Como en el estudio de: P. R. Davies, In Search of 'Ancient Israel' (Shaeffield 1992).

6 Véase, por ejemplo: P. Hanson - B. Janowski - M. Welker (eds.), Biblische Theologie, Beiträge des Symposiums "Das Alte Testament und die Kultur der Moderne" anlässlich des 100. Geburtags Gerhard von Rads (1901-1971), Heilderberg, 18.-20 Oktober 2001, ATM 14 (Münster 2005). 
En este apartado se trata, más bien, de cómo proponer un marco histórico verosímil al AT, es decir, de la reconstrucción plausible de la historia de Israel. Y es precisamente en este campo donde es posible advertir en la actualidad un gran cambio en cuanto a una nueva percepción de lo que es "historia bíblica» ${ }^{7}$. De hecho, para muchos investigadores, incluso este último término parece una aberración, prefieren utilizar términos más neutros como "historia del Levante» o reemplazar «época monárquica» por «edad del Hierro II $»^{8}$.

El gran cambio está dado por lo que algunos han definido como liberación de la historia del prejuicio bíblico. Y el diagnóstico que se hace es que la historia ha servido tradicionalmente como una especie de ancilla de la Biblia, buscando fundamentar el texto bíblico sirviéndose de las herramientas de las diversas disciplinas auxiliares de la historiografía? ${ }^{9}$. Es en este sentido que se la concede gran importancia a la arqueología llevada a cabo en el territorio de la actual Palestina y en las regiones vecinas.

En general, de la gran cantidad de aportes extrabíblicos es posible evidenciar la emergencia de una serie de coherencias e incoherencias en relación al texto. En el campo de las incoherencias más importantes es posible citar como ejemplo la ya trillada pregunta sobre la existencia histórica de importantes personajes biblicos: no solo me refiero a aquellos cuyas biografías parecen menos verosímiles, como Adán, Noé, e incluso Abraham, sino también a aquellos cuya existencia aparecía como firmemente establecida ${ }^{10}$, como David, Salomón, y otros.

El fenómeno de adjudicarle al relato bíblico mayor o menor verosimilitud histórica ha sido caracterizado actualmente en torno a la con-

7 Cf. M. Liverani, "Nuovi sviluppi nello studio della storia dell'Israele Biblico", Biblica 80 (1999) 488-505; I. Finkelstein - N. A. Silberman, La Biblia desenterrada, Una nueva visión arqueológica del antiguo Israel y de los origenes de sus textos sagrados (Madrid 2003) 22-27.

8 Como en la obra de: I. Finkelstein - N. A. Silberman, La Biblia desenterrada, Una nueva visión arqueológica del antiguo Israel y de los origenes de sus textos sagrados.

9 Véase por ejemplo el apartado «La storia d'Israele come ipertesto», en M. Liverani, Nuovi sviluppi, 489-490.

10 Cf. entre otros: G. N. Knoppers, «The Vanishing Solomon: The Disappearance of the United Monarchy from recent Histories of Ancient Israel», JBL 116 (1997) $19-44$. 
formación de dos tendencias ${ }^{11}$ : los llamados maximalistas y los minimalistas, e incluso de una tercera, los nibilistas.

En este contexto se ha de considerar un estudio como el de Israel Finkelstein y Neil Silberman, en su reciente obra The Bible Unearthed que parece exponer en, cierta medida, muy bien la tendencia actual en torno al tema de la contribución e importancia de la arqueología palestinense para la reconstrucción del pasado de Israel ${ }^{12}$. En resumen, el aporte más importante de esta obra, a mi entender, radica en la presentación que hace de una evidencia arqueológica fundamental: el estado de Judá no alcanzó un desarrollo urbano y cultural sino que hasta entrado el siglo VIII a. C., al mismo tiempo que se evidencia la expansión económica y social de Samaria en la etapa precedente.

En esta misma línea es posible comprender el creciente interés por los periodos persa y helenista como etapas fundamentales en la conformación de la identidad de Judá y de sus escrituras sacras. En este contexto, por ejemplo, aparece cada vez con mayor claridad la importancia del impacto helenista, entendido desde el punto de vista de la confrontación con el otro, de Judá/Israel y su entorno, como fundamentales para la conformación de su identidad religiosa en el contexto del AT.

Un desafío, aún pendiente, en este campo es una mayor clarificación del rol que jugaron las Escrituras dentro de este proceso histórico: qué fuerzas dieron origen a la labor de redacción y cómo se fue conformando un consenso social en torno a ellas.

\section{El estado actual de la investigación en torno al Pentateuco}

En el ámbito de los estudios relativos a los cinco libros del Pentateuco, lo más característico de la situación actual de la investigación está representado por el fin del consenso histórico que se había formado desde

11 Un buen resumen sobre esta temática en: L. L. Grabbe, A History of the Jews and Judaism in the Second Temple Period, vol. 1 (London-New York 2004), 11-13. Cf. también: D. V. Edelman, «Foreword», en L. K. Handy (ed.), The Age of Solomon. Scholarship at the turn of the millennium, SHCANE 11 (Leiden-New York-Köln 1997) xv-xx; B. Toro Icaza, La Historiografía del Antiguo Israel (Santiago 2004) 23-41; I. Finkelstein - N. A. Silberman, David y Salomón, En busca de los reyes sagrados de la Biblia y de las raices de la tradición occidental (Madrid 2007) 239-244.

12 I. Finkelstein - N. A. Silberman, La Biblia desenterrada, Una nueva visión arqueológica del antiguo Israel y de los orígenes de sus textos sagrados. 
fines del siglo XIX en torno a la llamada teoría de las fuentes de Julius Wellhausen ${ }^{13}$. Si bien es cierto que la teoría de Wellhausen nunca logró erigirse como la vía indiscutida para explicar la naturaleza y las dinámicas internas que caracterizan al actual texto del Pentateuco ${ }^{14}$, es cierto que en círculos muy amplios llegó a gozar de un estatus casi canónico.

¿Cómo se explica la caída en desgracia de esta teoría clásica? En realidad los motivos son diversos ${ }^{15}$ : el creciente escepticismo de los investigadores frente al llamado método histórico crítico, en especial frente a la posibilidad real de evidenciar fuentes o estratos diferentes en la redacción; esto unido al creciente interés por los métodos sincrónicos, en especial a los que acentúan la unidad literaria del texto y que por lo tanto explican tensiones presentes en los textos como un fenómeno de estilo; los aportes hechos por la arqueología palestinense en especial en lo referente a los orígenes de la escritura y alfabetización en dicho contexto, lo que obligaba a una datación mucho más tardía de los textos; como también la incapacidad de los cultores de la teoría de coincidir en algunos elementos gravitantes dentro de la misma.

Ahora bien, el hecho de desechar una teoría no significa necesariamente que se haya formado un nuevo consenso en torno a otra ${ }^{16}$. A todas luces aún tenemos que esperar para que se logre rearmar un mapa coherente. Lo importante es que nos movamos en la dirección correcta. En este sentido llama la atención, y me parece que este es un fenómeno positivo, la extrema cautela con que algunos autores presentan sus propuestas de solución. Por lo tanto, a continuación me propongo resumir lo que a mi entender es lo más pertinente al respecto.

En primer lugar no está de más recordar que el Pentateuco representa, sin duda, un texto complejo. Se trata a todas luces de una amalgama de materiales narrativos, legislativos, poéticos y cultuales, por mencio-

13 J. Wellhausen, Die Composition des Hexateuchs und der historischen Bücher des Alten Testaments (Berlin 1963).

14 Cf. R. N. Whybray, El Pentateuco, Estudio Metodológico (Bilbao 1995); R. RendTORfF, Das Alte Testament, Eine Einführung (Neukirchen-Vluyn 2007), 166-174; J. Van Seters, The Pentateuch, A Social-Science Commentary (London-New York 2004).

15 Cf. E. Zenger (ed.), Einleitung in das Alte Testament, Studienbücher Theologie 1,1 (Stuttgart 1995) 69-75.

16 En el sentido de «¡el Rey ha muerto! ¡Viva el Rey!». 
nar solo los tipos más importantes. Desde esta perspectiva es importante hacer hincapié en que cada sección tiene su propia originalidad: el Génesis es un libro muy diferente del Levítico, y estos dos a su vez del Deuteronomio. Al mismo tiempo, si nos concentramos en el libro del Génesis ${ }^{17}$, el llamado Ciclo de la Creación (111) representa un complejo que se diferencia en muchos aspectos del Ciclo de los Patriarcas (12-50). Así como al interior del Ciclo de los Patriarcas, las historias de Abraham, Jacob o José representan unidades con una identidad muy propia. Evidentemente esta situación precisa de una explicación.

Por otra parte está la pregunta de la unidad, y la identidad, del Pentateuco como conjunto. La que también precisa de una explicación, que debe, de alguna manera, armonizarse con la explicación que se proponga para la variedad de sus partes.

Dentro de la postura de cautela de la investigación actual, lo que está sucediendo, a mi entender, es recurrir en primer lugar a aquello que parece más seguro: se trata de la evidencia de material textual permeado particularmente por dos corrientes teológicas, una deuteronomista y otra sacerdotal.

El material deuteronomista se encuentra bastante acotado dentro del Pentateuco: el libro del Deuteronomio. Si bien es cierto que se pueden encontrar pasajes de estilo y teología deuteronomista en otros contextos, especialmente en el libro del Éxodo. El libro del Deuteronomio parece haber gozado durante un largo tiempo de una vida independiente. Su vínculo con el resto del Pentateuco es bastante precario. Esta independencia del Deuteronomio se refleja ya en el tratamiento que recibe en otras secciones de la literatura del AT. En cuanto a su origen y propósito, desde las teorías de De Wette, muchos han creído ver en él el testimonio de las reformas llevadas a cabo por Josías. Es decir representaría un texto cuyo origen se encuentra en época monárquica. Aún muchos adhieren a esta visión. A mí, personalmente, me parece que esta postura no es sostenible. El Deuteronomio representa un texto que solo pudo tener su origen a partir del postexilio.

Sobre las características propias de los diferentes ciclos del Génesis: V. M. Wilson, Divine Symmetries, The Art of Biblical Rhetoric (Lanham-New York-Oxford 1997), 77-105. 
Con los textos sacerdotales sucede algo un tanto diferente: si bien es cierto que el estilo y la teología sacerdotales son muy característicos (hasta cierto punto, inconfundibles) no se encuentran concentrados en un libro en particular (quizás con la excepción del libro del Levítico), sino que están entretejidos a lo largo del Pentateuco con otros textos.

¿Qué sucede con estos «otros textos»? Buena parte de estos son los que Wellhausen reconocía como yahvistas y elohístas. ¿Qué se puede decir con respecto a ellos? En primer lugar que no son datables en las etapas que suponía la teoría de las fuentes, sino que por el contrario parecen ser bastante modernos. En segundo lugar que no podemos aún reconocer a los autores o redactores que se encuentran detrás de ellos, pero sí la variedad de sus intereses: por ejemplo, ya Alonso-Schöckel había llamado la atención de la crítica con respecto a las perspectivas sapienciales presentes en el relato yahvista de Gn 2-3 ${ }^{18}$.

Esta nueva percepción en torno a la naturaleza del Pentateuco ha tenido como consecuencia un renovado interés por libros y los textos considerados a lo largo de la historia de la investigación como menos espectaculares: este es el caso del Levítico, que ha sido objeto de excelentes y novedosos estudios en esta nueva etapa ${ }^{19}$. Detrás de este renovado interés se percibe la intuición de los investigadores de que, probablemente, en estos textos se encuentran las respuestas y claves a muchas interrogantes.

Por último me gustaría subrayar al respecto: si bien aún no hemos llegado a la meta en cuanto a alcanzar un consenso en relación a la naturaleza y origen del Pentateuco, estamos en camino.

\section{Historiografía}

En primer lugar, se ha de notar la diferencia fundamental con el apartado segundo de este estudio: en el presente acápite no se trata de la «reconstrucción de la historia de Israel» a partir de todas las fuentes que sean aptas para esta empresa, sino que más bien de la comprensión de la naturaleza de la literatura de «corte histórico» presente en el AT.

18 L. A. SchöcKel, «Motivos sapienciales y de alianza en Gn 2-3», Biblica 43 (1962).

19 Un buen ejemplo es el estudio: D. Erbele-Küster, Körper und Geschlecht, Studien zur Anthropologie von Leviticus 12 und 15, WMANT 121 (Neukirchen-Vluyn 2008). 
Tendencias actuales en los estudios del Antiguo Testamento. Desafios y oportunidades $\mid 17$

En este campo un elemento gravitante está formado por todo el rubro de la investigación en torno a la llamada Obra o Historia Deuteronomistica ${ }^{20}(O D)$. Una figura clave en esta linea ha sido el investigador alemán Martin Noth ${ }^{21}$. Según la teoría clásica de Noth, la OD representaba un esfuerzo, realizado a la luz de las categorias del libro del Deuteronomio, por explicar el fracaso de la monarquía y el exilio de Israel. En base a esta intuición fundamental, Noth postulaba el origen, al menos, exílico de esta corriente teológica.

A partir de su trabajo precursor es posible observar la evolución de dos escuelas que recogen su impulso y lo desarrollan: la llamada escuela de Smed y la escuela de Cross. Rudolph Smed ${ }^{22}$ y sus seguidores, en fidelidad a la visión original de Martin Noth, adhieren al carácter exílico o postexílico de la $O D$, pero complementan la teoría con la postulación de la existencia de, al menos, tres niveles redaccionales: un deuteronomista histórico (DtrG), un deuteronomista profético (DtrP) y un deuteronomista legislativo (DtrN). En cambio Frank M. Cross ${ }^{23}$ aboga por una datación preexilica para la mayor parte del material y una redacción postexilica para los materiales que no se pueden incluir en esta categoria ${ }^{24}$. De hecho, la gran diferencia entre ambas escuelas es el rol adjudicado al texto de la reforma del rey Josías (2

20 Cf. M. O'Brien, Deuteronomistic History Hypothesis: A Reassessment, OBO 92 (Fribourg - Göttingen 1989); H. WeIPPERT, «Das deuteronomistische Geschichtswerk sein Ziel und Ende in der neueren Forschung», ThR 50 (1985) 213249; E. WürthweIn, Studien zum Deuteronomistischen Geschichtswerk, BZAW 227 (Berlin 1994); G. Braulik, "Die Theorien über das Deuteronomistische Geschichtswerk ("DtrG")», en E. Zenger (ed.) Einleitung in das Alte Testament, 127131; A. De Pury -T. Römer - J.-D. Macchi (eds.), Israël construit son Histoire. L'historiographie deutéronomiste a la lumière des recherches récentes (Genève 1996); T. RöMER, Dal Deuteronomio ai libri dei Re, Introduzione storica, letteraria e sociologica (Torino 2007).

21 Cf. M. Nотн, Überlieferungsgeschichtliche Studien (Tübingen 1957) 1-110. Si Heródoto, según Cicerón, era el «Padre de la Historia», entonces Martin Noth debería ser el «Padre de la Historia Deuteronomística». Véase también: H.D. HoffMAN, Reform und Reformen. Untersuchungen zu einem Grundthema der deuteronomistischen Geschichtsschreibung, AThANT 66 (Zürich 1980).

22 Cf. R. Smend, Die Entstehung des Alten Testaments, ThW 1 (Stuttgart-BerlinKöln-Mainz 1984).

23 Cf. F. Moore Cross, Canaanite myth and Hebrew epic: essays in the history of the religion of Israel (Cambridge 1973).

24 Cf. R. D. Nelson, The Double Redaction of the Deuteronomistic History (Sheffield 1981). 
Reyes 22-23). Para Cross, no solo el libro del Deuteronomio es fruto de la reforma, sino que también casi la totalidad de la $O D$.

A mi entender, y es aquí donde se ha concentrado parte importante del debate actual, la gran dificultad de la teoría de Cross y sus adeptos es la imposibilidad de probar fehacientemente la existencia de una reforma josíana y la vinculación de los escritos deuteronomistas con dicha reforma. Después de todo el texto del libro de Reyes representa en sí mismo un fruto del trabajo de la escuela deuteronomista. Se trata de la gran dificultad metodológica de encontrar un punto arquimediano para reconstruir la historia del Israel monárquico y por ende la naturaleza de la OD.

En acérrima contraposición a la escuela de Cross y otras posturas afines encontramos en la actualidad a la llamada "escuela escandinava» ${ }^{25}$, que se ha erigido como el baluarte de una propuesta de datación postexílica de prácticamente la totalidad del AT. Y no es difícil, para cualquier observador imparcial, detectar que la tendencia de la investigación se desarrolla en esta dirección.

Los representantes de la escuela escandinava, han aportado categorías vigentes en el campo de otras ciencias, en especial la sociología: en este caso plantean la pregunta sobre el tipo de sociedad que produjo estos textos y por qué los textos son como son. Se trata según el parecer de estos autores de una «sociedad colonial», creada a partir del exilio por las políticas imperiales foráneas (la administración persa) a partir de motivaciones económicas, estratégicas e ideológicas específicas. Por lo tanto la pregunta en este ámbito, como en otros del AT, es cómo los textos buscan responder a esta situación social.

Al concluir este apartado, desearía hacer mención al problema de fondo, que a mi parecer determina la discusión actual, y el que sin duda aún precisa de una mayor elaboración por parte de la investigación. Se trata de la compleja interacción de la historia y la teología. A este tema $y$ algunas de sus implicaciones ya me he referido en otro estudio ${ }^{26}$, por lo tanto no es mi intención explayarme aquí. Solo me parece importante recordar la importancia que le atañe a la historiografía como constructora de identidad y hermeneuta del presente.

25 Sobre la escuela escandinava véase: I. CHuecas, «Credibilidad y Sagrada Escritura», Teología y Vida 46 (2005), 233-234.

26 I. Chuecas, «Credibilidad y Sagrada Escritura», 230-234. 


\section{Profecía}

También en el campo de la literatura profética es posible percibir la creciente apelación de los investigadores hacia la necesidad de una reingeniería. Al igual que en los otros campos del estudio del AT esta necesidad aparece asociada al concepto sobre el plantear las preguntas correctas. En cierto sentido, esta nueva impostación representa, también ella, una parte de la crisis del método histórico crítico tradicional, que como sabemos se había empeñado en una búsqueda de los niveles más antiguos de la redacción ${ }^{27}$.

En el caso de los textos de los libros proféticos el fenómeno más característico, a mi entender, es el creciente alejamiento de la figura del actor profético como tradicionalmente se entendió ${ }^{28}$ : el método histórico crítico partía de la base que en el núcleo o el origen del texto existía la personalidad de un profeta, cuyo mensaje daba identidad al texto. De este profeta era posible inferir su biografía, su contexto histórico y social, sus motivaciones, e incluso su psicología. Esta impostación tradicional había llevado a toda una elaboración teórica en cuanto a la identidad del profeta y de su profecía, la que muchas veces se hallaba en abierta contradicción a los postulados de los mismos autores en cuanto a la evolución del texto. Esta visión del texto como testimonio directo de la actividad de un individuo es lo que, según mi opinión, más profundamente está cambiando el rostro de los estudios de estos textos ${ }^{29}$.

En la actualidad no solo cada vez se asienta más la noción de que los libros representan una obra colectiva llevada a cabo durante un lapsus muy extenso (en algunos casos a lo largo de varios siglos), sino que lejos de representar una actividad profética, por así decir espontánea, repre-

27 Cf. J. Blenkinsopp, A History of Prophecy in Israel, revised and enlarged (Louisville 1996), 16-26.

28 Cf. el apartado 'Prophecy' as a Largely Literary Product en: P. R. DAvies - J. Rogerson, The Old Testament World (Louisville 2005), 169-171. Un ejemplo de este fenómeno en un libro concreto en: T. HadjIEv, The Composition and Redaction of the Book of Amos (Berlin-New York 2009), 1-25.

29 A pesar que todavía persiste en especial entre los autores de lengua española, véase por ejemplo: L. A. Schöckel - J. L. Sicré Díaz, Profetas (Madrid 1985); J. M. Abrego de Lacy, Los libros proféticos, Introducción al estudio del Biblia 4 (Estella 1993); J. L. Sicré, Profetismo en Israel. El profeta. Los Profetas. El Mensaje (Estella 1992). 
sentan un tipo de literatura, valga la redundancia, artística, al mismo modo de la historiografía, poesía o la apocalíptica: es decir, literatura de escriba y por lo tanto de escritorio. De hecho, si fuese necesario precisar cuál sería el tipo de texto bíblico más cercano a la profecía, sin duda habría que reconocer que son los textos de corte poético.

Un segundo fenómeno fundamental está representado por la centralidad atribuida en conformación de la profecía al momento histórico del exilio. En la medida que se ha ido creando lentamente también en este ámbito un consenso sobre el origen postexílico de los textos, al mismo tiempo este ha ido ganado en importancia como clave hermenéutica para comprender el origen, no de la profecía de Israel en general, sino de los textos de los libros proféticos que conocemos y sus opciones teológicas. En esta medida es posible comprender y muchas veces volver a descodificar categorías básicas de la teología profética, tales como: castigo y culpa, salvación y restauración, conversión y retorno, fidelidad e idolatría, polémica contra la monarquía y el sacerdocio, intolerancia contra los extranjeros y universalismo, crítica social y denuncia cultual.

$\mathrm{Al}$ igual que en otros ámbitos, también en este han ido ganando importancia los aportes provenientes de otras disciplinas, tales como la arqueología y los estudios comparados con la filología y cultura del Antiguo Oriente ${ }^{30}$.

\section{SABiduría}

Las nuevas impostaciones de la investigación ciertamente están generando un impacto en el área de los llamados escritos sapienciales y, al mismo tiempo, nos están llevando a una revaloración de la tradición sapiencial y de su aporte fundamental a la teología del $\mathrm{AT}^{31}$. En esta línea podemos enmarcar la afirmación sobre la sapiencialidad de todo el AT, el cual como fruto de una tradición y de una actividad literaria representa, por lo tanto, el resultado de la labor paciente de los sabios de Israel ${ }^{32}$. En este sentido, toda forma de literatura, en Israel y en el mundo antiguo, es

$30 \mathrm{Al}$ respecto véase, por ejemplo: M. Nissinen (with contributions by C. L. SEOw R. K. Ritner), Prophets and Prophecy of the Ancient Near East (Atlanta 2003).

31 Cf. el trabajo fundamental de: J. L. Crenshaw, Old Testament Wisdom. An Introduction (Louisville ${ }^{3} 2010$ ).

32 Cf. P. R. Davies, Scribes and Schools, The Canonization of the Hebrew Scriptures (Louisville 1998). 
sapiencial. Esta expansión del concepto de lo sapiencial ha traído como consecuencia, y a su vez se origina en la constatación de la presencia de textos de tipo sapiencial en el Pentateuco, la Historiografía y la Profecía, por mencionar las áreas más relevantes.

Antes de esbozar algunos de estos es necesario tener presente que este campo no se trata de un corpus unitario: entre ellos encontramos literatura poética, cultual, de edificación. Esta naturaleza variada evidentemente llama a una aproximación a través de una pluralidad de formas. También es necesario tener presente que por lo general existen, como música de fondo, ciertos acentos de la literatura sapiencial que presuponen opciones más evidentes que el resto de la literatura del AT: como por ejemplo la influencia del tema de la diáspora en el librito que narra la historia de Ester.

Aun considerando las grandes diferencias cualitativas existentes entre los textos de este corpus, ¿es posible definir algunos rasgos comunes entre ellos? A mi entender, y realizando una fuerte generalización, me parece que hoy es posible afirmar que la literatura sapiencial tiene como elemento común una reflexión sobre el hombre y su lugar en el mundo. Este interés por el hombre y su entorno caracterizan fuertemente la mentalidad sapiencial, determinando en ella una impostación marcadamente profana. Un buen ejemplo de esta perspectiva es la tan comentada, y a veces incómoda, profanidad, e incluso ateísmo del Cantar de los Cantares de Salomón.

Entre las muchas aproximaciones novedosas al campo de los escritos sapienciales merece especial mención la hermenéutica feminista. Es en este campo donde es posible percibir un importante y original aporte de las temáticas relativas al rol de la mujer y de lo femenino, sobre todo desde el punto de vista de la conformación de un imaginario teológico ${ }^{33}$.

\section{Desafíos para la sistemática}

En realidad todo el presente estudio está concebido como un planteamiento de desafíos a partir del estado actual de la investigación del AT. A partir de esta observación, es mi opinión particular, que se trata más bien de la labor de la teología sistemática la de esforzarse por extraer las

33 Como por ejemplo el excelente estudio: C. V. CAmp, Wise, Strange and Holy. The strange woman and the making of the Bible, JSOTSup 320 (Sheffield 2000). 
consecuencias para su propia disciplina. Aun así, de entre los desafíos ya enunciados, por ejemplo, un tema que es necesario trabajar más por parte de la teología sistemática, pero no solo desde un punto de vista teórico, sino que práctico, es el de la relación existente entre historia y teología.

A continuación paso a enunciar simplemente un par de temas que me parecen son relevantes y que pueden servir de ejemplo de desafíos.

El valor de la «teología narrativa»

El cambio paradigmático en cuanto a la naturaleza literaria de los textos presenta, a mi modo de ver, una doble interpelación a nuestro modo de hacer teología.

Por una parte exige incorporar los resultados de este tipo de investigaciones y adecuarse a ellos: por ejemplo en relación a la naturaleza literaria de los textos proféticos.

Por otra parte, y especialmente en el discurso de la teología sistemática, que como su nombre lo dice es hija de la necesidad de sistematizar, en la línea de las formas de pensamiento imperantes en Occidente desde la antigüedad grecorromana, se hace imperativo el desafío de incluir una forma de desarrollar el pensamiento teológico desde una perspectiva que podríamos definir como teología narrativa. La praxis teológica de Jesús en los evangelios, muy de acorde con las tradiciones del AT, podría representar una pista en esta dirección. Al mismo tiempo esta impostación narrativa o poética implica explorar y desarrollar el lugar que ocupa la expresión artística como vía teológica, como lo expresa el estudio clásico de Robert Alter: «The Art of Biblical Narrative».

Origen de la religión de Israel

La teología sistemática, en su afán por sistematizar, suele recurrir a esquemas, muchas veces con una cierta tendencia fosilizante, para describir procesos y evoluciones. Un ejemplo de esto son las teorías que describen una evolución desde el politeísmo al monoteísmo en el antiguo Israel, muy utilizadas por la sistemática en el campo de la representación de la noción del Dios uno y sus orígenes.

Una comparación de estas teorías con los datos emergentes del AT demuestra que aquellas tienden a ser un producto del imaginario de los teólogos y revelan no solo una noción ingenuamente evolucionista, sino 
que un desconocimiento fundamental del AT como un conjunto de textos generados en el marco de una situación bastante particular: con posterioridad al exilio, como sea que nos podamos imaginar a este, cuando el monoteísmo era una situación consagrada, al menos en los círculos que produjeron los textos y con una visión no solo abiertamente beligerante en relación a las religiones foráneas, sino que también con un altísimo grado de desconocimiento de ellas.

El AT no representa tanto un testimonio de una evolución, sino que más bien una radiografía de una etapa determinada. Esta situación significa, lamentablemente para algunos, que no conocemos a ciencia cierta los orígenes. Existen algunas pistas: como la existencia, evidenciada por la arqueología de una religiosidad de tipo popular en el Israel del Hierro II en la cual parecen convivir diferentes tradiciones religiosas ${ }^{34}$, una situación que parece extenderse hasta entrado el periodo de la ocupación romana; y que, por otra parte, en la conformación del monoteísmo yahvista jugó un papel principal la provincia de Judá, junto con su Templo y los grupos religiosos que lo componían.

La precariedad de la teología

Por lo tanto, cómo se realizó este paso del yahwismo primitivo al judaísmo, simplemente no lo sabemos. Este no saber implica un último desafío que me gustaría mencionar: aceptar que existen fronteras para nuestra teología y asumir las consecuencias que estos límites nos imponen.

En especial en el marco de nuestra actividad docente me parece esencial que reconozcamos con honestidad y sencillez que no tenemos todas las respuestas, que el quehacer teológico significa muchas veces caminar a tientas, y que las respuestas que encontramos muchas veces generan mil incógnitas.

34 Se puede consultar al respecto el polémico libro: W. G. Dever, Did God Have a Wife? Archeology and Folk Religion in Ancient Israel (Grand Rapids-Cambridge 2005). 
Resumen: El presente artículo pretende hacer una presentación muy sucinta del estado actual de la investigación en el campo de los estudios del Antiguo Testamento. Al mismo tiempo, se intenta que esta introducción en la problemática actual sea accesible para un público que no necesariamente se ha especializado en la materia, pero que sí maneja algunas categorías teológicas fundamentales, en especial desde la perspectiva de la teología sistemática. La exposición comienza haciendo referencia al cambio más importante en cuanto a la forma de enfrentar el estudio de los textos del Antiguo Testamento, haciendo también especial referencia al tema histórico. Más tarde se procede a hacer una presentación según los ámbitos más característicos: Pentateuco, Obra Deuteronomista, Profetas y Escritos Sapienciales. Por último se concluye presentando algunos desafíos particulares en relación a la interacción de la teología veterotestamentaria y la sistemática.

Palabras clave: Antiguo Testamento, investigación actual, historia, pentateuco, profetas, sapienciales, teología sistemática.

Abstract: This article aims to briefly present the current state of research in the field of Old Testament studies. At the same time, the introduction to this issue is intended to be accessible to an audience who is not necessarily specialized in the field, but who is knowledgeable in some fundamental theological categories, particularly from the perspective of systematic theology. The presentation begins by referring to the most important change in terms of the ways to face the study of Old Testament texts, also making special reference to the historical aspect. Further, it proceeds to make a presentation according to the most characteristic areas: Pentateuch, Deuteronomistic work, Prophets and Wisdom Writings. Finally, it concludes presenting some particular challenges in relation to the interaction of the Old Testament theology and systematic theology.

Keywords: Old Testament, current research, history, pentateuch, prophets, wisdom, systematic theology. 